Keywords: epidermal growth factor; microarray; migration; mucosa-associated lymphoid tissue 1; oral cancer; transforming growth factor- $\beta$

\title{
Inhibition of TGF- $\beta$ and EGF pathway gene expression and migration of oral carcinoma cells by mucosa-associated lymphoid tissue 1
}

\author{
Y Ohyama ${ }^{1}$, Y Kawamoto ${ }^{1}$, T Chiba ${ }^{2}$, G Maeda ${ }^{2}, \mathrm{H}_{\text {Sakashita }}{ }^{1}$ and K Imai ${ }^{\star}{ }^{2}$ \\ ${ }^{1}$ Department of Oral and Maxillofacial Surgery 2, Meikai University, 1-1 Keyakidai, Sakado, Saitama 350-0283, Japan and \\ ${ }^{2}$ Department of Biochemistry, School of Life Dentistry at Tokyo, The Nippon Dental University, 1-9-20 Fujimi, Chiyoda-ku, \\ Tokyo 102-8159, Japan
}

Background: Expression of mucosa-associated lymphoid tissue 1 (MALT1) is inactivated in oral carcinoma patients with worse prognosis. However, the role in carcinoma progression is unknown. Unveiling genes under the control of MALT1 is necessary to understand the pathology of carcinomas.

Methods: Gene data set differentially transcribed in MALT1-stably expressing and -marginally expressing oral carcinoma cells was profiled by the microarray analysis and subjected to the pathway analysis. Migratory abilities of cells in response to MALT1 were determined by wound-healing assay and time-lapse analysis.

Results: Totally, 2933 genes upregulated or downregulated in MALT1-expressing cells were identified. The subsequent pathway analysis implicated the inhibition of epidermal growth factor and transforming growth factor- $\beta$ signalling gene expression, and highlighted the involvement in the cellular movement. Wound closure was suppressed by wild-type MALT1 (66.4\%) and accelerated by dominant-negative MALT1 (218.6\%), and the velocities of cell migration were increased 0.2-fold and 3.0-fold by wild-type and dominant-negative MALT1, respectively.

Conclusion: These observations demonstrate that MALT1 represses genes activating the aggressive phenotype of carcinoma cells, and suggest that MALT1 acts as a tumour suppressor and that the loss of expression stimulates oral carcinoma progression.

Squamous cell carcinoma is a most common malignant neoplasm of the oral cavity. The patient prognosis is still worse than that of all cancers combined, and the annual incidence of new cases is predicted to increase in the next few decades (Choi and Myers, 2008; Siegel et al, 2012). Phenotypic alterations of carcinoma cells result from the aberrations of endogenous and exogenous factors, and select aggressive clones to progress carcinomas to the more advanced states. Understanding molecular mechanisms of carcinoma progression and developing the new therapeutic approach are prerequisite for the improvement of prognosis.

Oral carcinoma cells frequently inactivate tumour-suppressive proteins during the disease progression (Choi and Myers, 2008). Our previous study demonstrated that mucosa-associated lymphoid tissue 1 (MALT1) is expressed in the nucleus of oral epithelial cells (Chiba et al, 2009) and substitutes keratins depending on its expression (Kawamoto et al, 2013). The advanced carcinomas inactivate MALT1 expression by the promoter methylation, and the loss of expression worse the patient prognosis (Chiba et al, 2009). However, nothing is known about the role of loss of expression in the carcinoma progression at present. The MALT1 is made up of three types of domain: a death domain, Iglike domains, and a caspase-like domain. The B-cell or T-cell receptor antigen signals oligomerise MALT1 with BCL10 and CARMA1/3 into a CBM complex. The MALT1 interacts with BCL10 through its Ig-like domains and induces I $\kappa$ B-kinase catalytic activity, resulting in nuclear factor $-\kappa \mathrm{B}(\mathrm{NF}-\kappa \mathrm{B})$ activation in lymphocyte lineages (Thome, 2008; McAllister-Lucas et al, 2011). Unveiling gene data sets that are regulated by MALT1

*Correspondence: Professor K Imai, E-mail: kimai@tky.ndu.ac.jp

Received 3 January 2013; revised 1 April 2013; accepted 20 May 2013; published online 18 June 2013

(c) 2013 Cancer Research UK. All rights reserved 0007-0920/13 
substantiates the role of loss of expression in the carcinoma progression. In this study, we investigated the gene data sets and pathways by microarray analysis and determined the effect on carcinoma cell phenotype by migration assays.

\section{MATERIALS AND METHODS}

Cell lines. HSC2 oral carcinoma cells, which marginally express MALT1, were obtained from the Cell Resource Center for Biomedical Research Institute of Development, Aging and Cancer (Tohoku University, Sendai, Japan). HSC2 cells stably expressing FLAG-tagged full-length wild-type MALT1 (wtMALT1 HSC2 cells) and the $\mathrm{NH}_{2}$ terminal death and Ig-like domains-deleted dominant-negative MALT1 ( ${ }_{\triangle \mathrm{MALT1}} \mathrm{HSC} 2$ cells; Che et al, 2004) and transfected vector alone (mock HSC2 cells) were established previously (Chiba et al, 2009). They were maintained in $10 \%$ fetal bovine serum and 100 units per $\mathrm{ml}$ of penicillin/streptomycincontaining DMEM (Sigma-Aldrich, St. Louis, MO, USA) in a conventional $5 \% \mathrm{CO}_{2}$ incubator.

Microarray analysis. Gene-expression profile was measured with RNA extracted from wtMALT1 HSC2 cells and mockHSC2 cells and processed for aRNA synthesis, labelling, and hybridisation by Mitsubishi Chemical Mediscience, Inc. (Tokyo, Japan). First-strand cDNA synthesis with $100 \mathrm{ng}$ of total RNA, synthesis of biotinlabelled aRNA, and clean up were carried out using GeneChip 3'IVT Express Kit (Affymetrix Japan, Tokyo, Japan). For hybridisation, $15 \mu \mathrm{g}$ of fragmented aRNA was incubated with GeneChip Human Genome U133A 2.0 in $250 \mu$ l of hybridisation solution in GeneChip Hybridization Oven 640 (Affymetrix Japan) at $45{ }^{\circ} \mathrm{C}$ for $16 \mathrm{~h}$. GeneChips were then washed and stained with GeneChip Fluidics Station 450 (Affymetrix Japan) according to manufacturer's instruction. Microarrays were scanned with GeneChip Scanner 3000 (Affymetrix Japan), and the signals were processed using GeneChip Command Console Software (AGCC, Affymetrix Japan). The scanned images were first assessed by visual inspection, then analysed to generate raw data files saved as CEL files using the default setting of AGCC. Robust Multichip Analysis was used to normalise the different arrays, and further analysis was carried out with GeneSpring GX10 (version 11.5.1, Agilent Technologies, Inc., Tokyo, Japan). Three replicates were used for microarray analysis and statistics. To find differentially expressed genes, we used Aspin-Welch's paired $t$-test and considered the significance when the $P$-value was below 0.05 . The Benjamini-Hochberg false discovery rate (FDR) method was used to correct for multiple testing effect. Probe sets were considered to have changed qualitatively in a specific comparison if an adjusted $P$-value of 0.05 was obtained. Their normalised data were used to generate a list of differentially expressed genes between wtMALT1 HSC2 cells and mock HSC2 cells when they had an absolute change of $\geqslant 2$-fold. Gene-expression changes that met these criteria were termed as 'significant RNA state change' and had directional qualities of 'up' or 'down' (i.e., they can be upregulated or downregulated in wtMALT1 HSC2 cells). The data discussed in this publication have been deposited in NCBI's Gene Expression Omnibus (Edgar et al, 2002) and are accessible through GEO Series accession number GSE42335 (http://www.ncbi.nlm.nih.gov/geo/query/acc.cgi?acc=GSE42335).

Functional and pathway analyses of differentially expressed genes. The differentially expressed gene list was ranked according to their fold changes and compared with sets of genes that were annotated according to the gene ontology (GO) for molecular function, cellular component, and biological process (Ashburner et al, 2000). Results with $P$-value $\leqslant 0.05$ and FDR were used identify canonical pathways associated with the differentially expressed genes by uploading the list into the Ingenuity Pathway
Analysis (IPA) website (version 9.0, http://www.ingenuity.com). Briefly, the Ingenuity Knowledge base contains information from scientific publications regarding direct and indirect relationships between genes and proteins. Each identifier was mapped to its corresponding gene object in the Ingenuity knowledge base. These genes, called focus genes, were overlaid onto a global molecular network in the Ingenuity knowledge base. Networks of these focus genes were then algorithmically generated based on the information available in the IPA web site. All of the differentially expressed genes were included in the analysis, and ranked according to $P$-value (Mori et al, 2009). In figures represented in this study, the upregulated genes were marked with red and the downregulated genes with green with the intensity of the colour being an indicator of the fold of expression.

Real-time PCR. Total RNA extracted from cell lines was reverse transcribed to cDNA by MultiScribe Reverse Transcriptase (Applied Biosystems, Foster City, CA, USA) and subjected to real-time PCR using the StepOne Real-time PCR system (Applied Biosystems). PCR conditions were $95^{\circ} \mathrm{C}$ for $20 \mathrm{~s}$ followed by 40 cycles of $95^{\circ} \mathrm{C}$ for $1 \mathrm{~s}$ and $60^{\circ} \mathrm{C}$ for $20 \mathrm{~s}$. The TaqMan probes (Applied Biosystems) specific for LXN (Hs00220138_m1), TFF1 (Hs00907239_m1), GATA3 (Hs00231122_m1), TP53 (Hs01034249_ $\mathrm{m} 1), \quad C D H 1$ (Hs00170423_m1), FABP4 (Hs01086177_m1), FABP6 (Hs01031183_m1), VEGFC (Hs00153458_m1), SNAI2 (Hs00950344_m1), HMGA2 (Hs00171569_m1), IL6ST (Hs00174360_m1), CDH2 (Hs00983062_m1), PXN (Hs01104424_ m1), and IL11 (Hs01055413_g1) were used. Expression levels were normalised against ACTB (TaqMan Endogenous Control Human $A C T B$, Applied Biosystems). Levels of gene expression $\left(2^{-4 \Delta C t}\right)$ were determined by the standard curve method (Schmittgen and Livak, 2008).

Immunoblot. Total cell lysates were used for the immunoblot with a standard protocol. The lysates in the SDS sample buffer containing $1 \mathrm{~mm}$ phenylmethanesulphonyl fluoride and a protease inhibitor cocktail (Roche Diagnostics GmbH, Mannheim, Germany) were size fractionated by SDS-PAGE gels under reducing conditions and electrotransferred onto PVDF membranes. The membrane was probed with antibodies specific to TFF1, GATA3 (Santa Cruz Biotechnology, Santa Cruz, CA, USA), LXN (R\&D Systems, Minneapolis, MN, USA), FABP4, FABP6, or $\beta$-actin (Sigma-Aldrich).

Wound-healing and migration assays. Subconfluent cell monolayer $(80-90 \%$ confluency) with or without MALT1 shortinterfering RNA (siRNA) transfection (50 nM; \#18601 siRNA; Ambion, Austin, TX, USA) was maintained in $1 \%$ fetal bovine serum-containing culture medium. Silencer Negative Control \#1 siRNA (Ambion) was used as a negative control. Wounds were created by the scratch using a pipettman tip and cultured up to $48 \mathrm{~h}$. The wound closure was evaluated by measuring the width of the remaining wound (Sossey-Alaoui et al, 2005). The real-time cell electronic sensing assay based on electrical impedance readings in cell monolayers plated in wells containing built-in gold electrodes was performed. We have used the analyzer (xCELLigence RTCADP), 16-well e-plates and the integrated software (Roche Diagnostics $\mathrm{GmbH}$ ). The RTCA System works by measuring the electronic impedance at the cell-sensor electrode interface integrated on the bottom of e-plates ( $\mathrm{Yu}$ et al, 2006). For timelapse microscopy, wtMALT1 HSC2 cells, $\triangle$ MALT1 HSC2 cells, and mock HSC2 cells were labelled with CellTracker Green Fluorescent Probe (Lonza, Walkersvill, MD USA) and seed onto 35-mm plastic dishes. After $10 \mathrm{~h}$, the single cell migration was monitored using a laser scanning microscope (LSM 700; Carl Zeiss, Oberkochen, Germany) equipped with a transparent environmental chamber (Climabox, Carl Zeiss) under $5 \% \mathrm{CO}_{2}$ in air at $37^{\circ} \mathrm{C}$. The microscope was driven by the IMARIS (Carl Zeiss) every $10 \mathrm{~min}$ 
during $16 \mathrm{~h} \quad(n=4)$. Cell migration was characterised and quantified using an interactive tracking method (Zahm et al, 1997).

Statistical analysis. Statistical analyses on the data manipulation for microarray analysis were indicated above. Percentage of wound closure and migration velocities was analysed by Wilcoxon test using JMP 7.0.1 (SAS Institute Inc., Cary, NC, USA).

\section{RESULTS}

Genes regulated by MALT1. Genes expressed in ${ }_{\text {wtMALT1 }} \mathrm{HSC} 2$ cells and mock HSC2 cells were initially compared by the microarray analysis, and 2933 genes with a fold change of $\geqslant \pm 2.0$ and with the $P<0.05$ were specified (Figure 1A). They included 1433 upregulated and 1500 downregulated genes in wtMALT1 HSC2 cells. Strict filtering of normalised intensity value with a fold change of $\geqslant \pm 10.0$ (415 probe sets) showed that the upregulated genes ( $n=328$; fold change, $120.5 \pm 580.2$, mean \pm s.d.) were more robustly changed than the downregulated genes $(n=87$, $21.2 \pm 16.0 ; P=0.002$; Figure $1 \mathrm{~B})$. Top 10 for each was shown in Table 1 (complete list was shown in Supplementary Table 1).

Validation of microarray data. Quantitative real-time PCR was done to validate the genes expressed at various levels, and confirmed the expression in an almost same pattern of the microarray analysis (Figure 1C). The differential protein expression encoded by representative genes that suppress ( $L X N, T F F 1$, and GATA3) and stimulate (FABP4 and FABP6) carcinoma progression
(Ohmachi et al, 2006; Kouros-Mehr et al, 2008; Li et al, 2011; Nieman et al, 2011; Soutto et al, 2011) was substantiated at the protein level (Figure 1D). Although expression of other genes was not validated in this study, many of downregulated genes associate with oral carcinoma progression such as TWIST1, LMO4, ZEB2, WNT3, and MMP14 (Shimada et al, 2000; Mizunuma et al, 2003; Uraguchi et al, 2004; Maeda et al, 2005; Okamura et al, 2009).

GO and pathway analyses. To analyse the function of MALT1responsive genes, all data sets of genes were first evaluated by the GO analysis. It suggested that the genes are involved in inter- and intra-cellular signalling, cellular organisation, and developmental processes (Table 2). The IPA top three bio-functions were 'Cancer', 'Cellular Movement', and 'Gastrointestinal Disease', and canonical pathways were 'HER2-Signalling in Breast Cancer', 'Glioma Invasiveness Signalling', and 'Role of Tissue Factor in Cancer' (Figure 2). The list with $P<0.05$ and threshold value of $-\log$ $(P$-value $), 0.05$, were summarised in Supplementary Table 2. Other classification of our interests that were not included in the GO analysis but closely correlated with carcinoma progression including extracellular matrix-degrading enzymes, collagens, laminins, integrins, WNT pathways, and cancer and/or epidermal stem cell markers were listed in Supplementary Table 3.

The pathway analysis was performed on all genes identified with an absolute change of $\geqslant 2$-fold. Since the IPA showed a most close association of the gene data sets to 'Cancer', we overviewed 'Molecular Mechanisms of Cancer' to identify the signalling pathway network affected by MALT1. Ras and SMAD pathways occupied central positions in the network (Supplementary
A

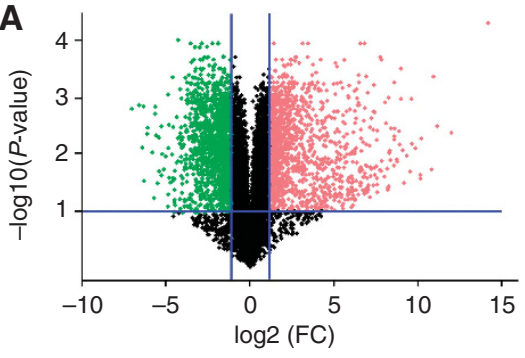

C

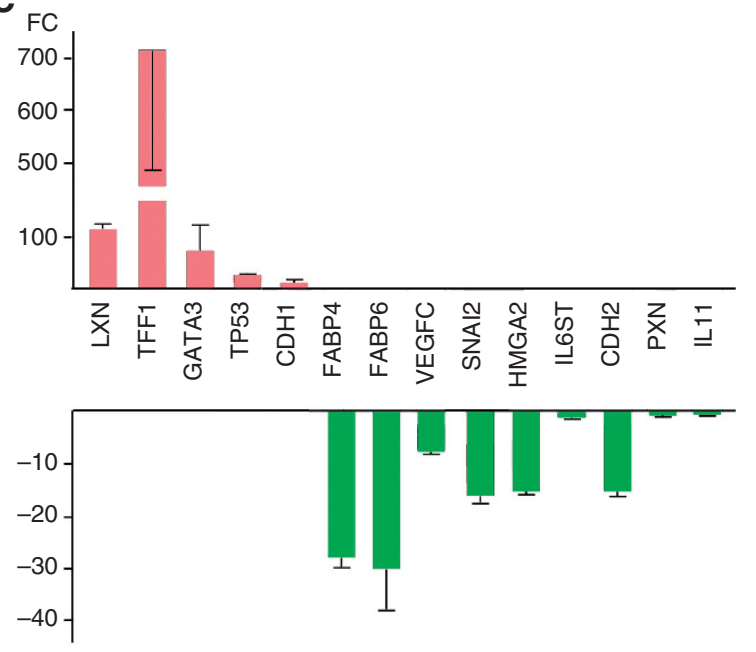

B (i)

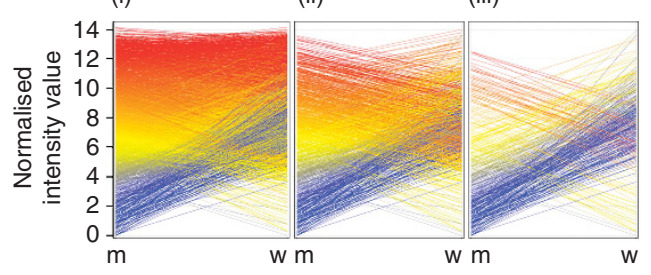

D

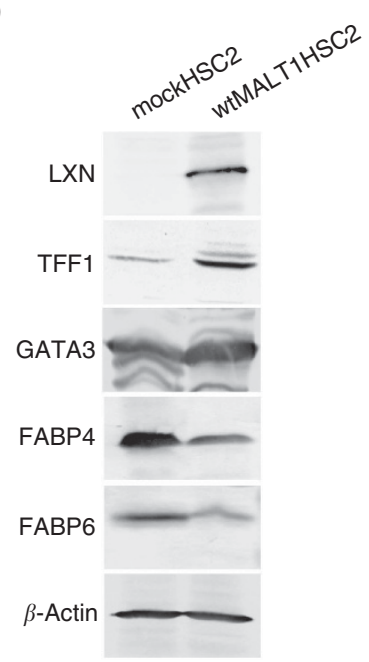

Figure 1. Microarray analysis and its validation by real-time PCR and immunoblot. Log2 fold-change $(F C)$ and their corresponding -log10( $P$-value) of all genes in the microarray were taken for construction of the volcano plot. Genes upregulated and downregulated $>2.0-$ fold change with a $P$-value of $<0.05$ were depicted in light red and green, respectively. All other genes that were not significantly altered were in black (A).

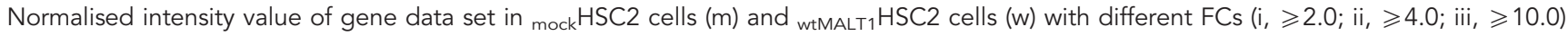
was illustrated. Genes upregulated and downregulated in wtMALT1 HSC2 cells were depicted in blue and red, respectively (B). Expression of genes of interests was analysed by quantitative real-time PCR $(n=3)$. FC of genes of interests in ${ }_{\text {wtMALT1 }} \mathrm{HSC} 2$ cells relative to mock HSC2 cells were standardised by the expression of ACTB (C). Protein expression was examined by the immunoblot. $\beta$-actin was used as an internal control (D). 


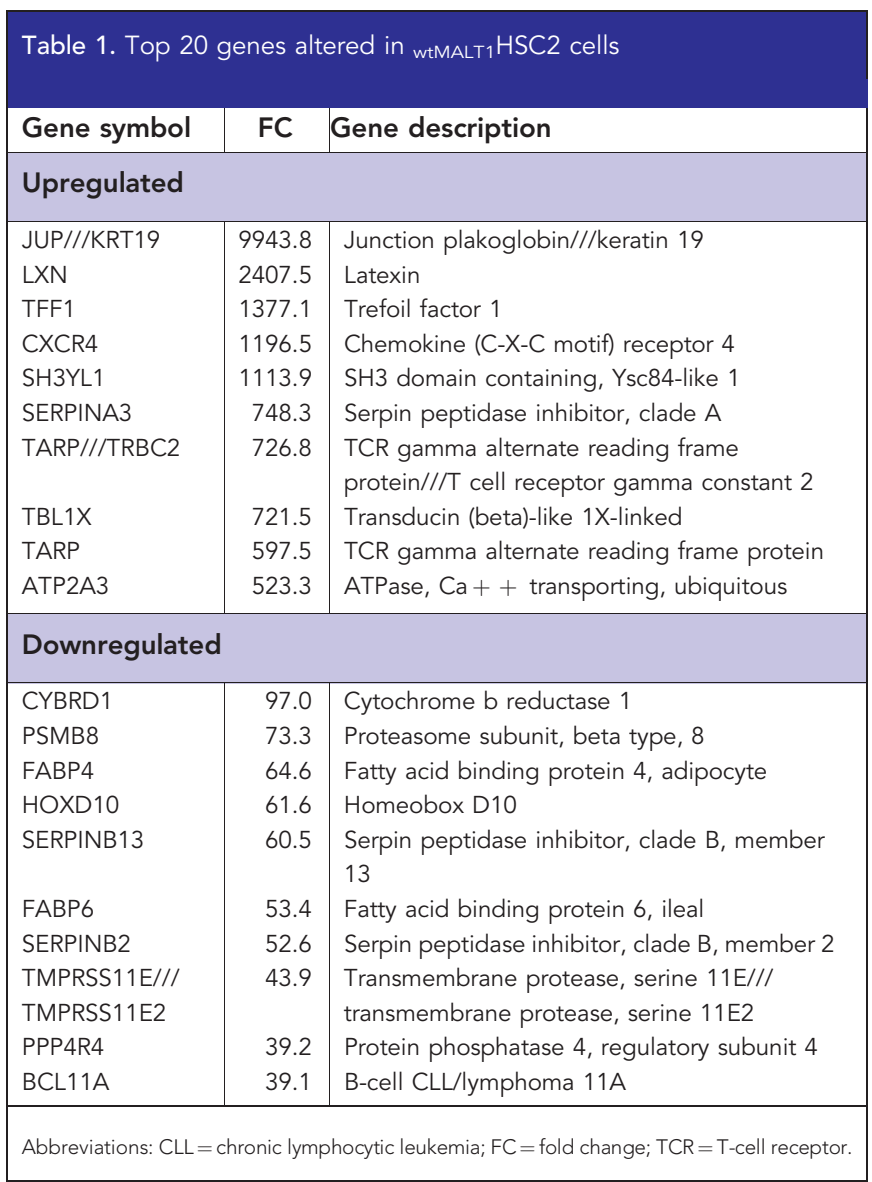

Figure 1). ErbB1 and its ligands (AREG, TGF- $\alpha$, EREG, and NRG1) and signalling molecules (RAS, PI3K, and PKC) listed in 'ErbB Signalling' were downregulated (Figure 3A). TGF- $\beta$ pathway genes for TGF- $\beta$, TGF- $\beta$ receptor II, and Smad-2/3/4 (Figure 3B) and many FAK signalling genes, including ITGs, EGFR, RHAMM, $V C L, P X N$, and DOCKs, were downregulated (Supplementary Figure 2). Although MALT1 is well known to activate NF- $\kappa$ B in lymphocyte lineages (McAllister-Lucas et al, 2011), there was no definite predisposition for genes involved in NF- $\kappa \mathrm{B}$ activation (Supplementary Figure 3).

Enhanced migration by loss of MALT1 expression. The IPA biofunction analysis suggested a close association of MALT1 in 'Cellular Movement', and enhanced migration is a representative phenomenon of the aggressive behaviours of carcinoma cells (Hanahan and Weinberg, 2011). Therefore, migration of wtMALT1 HSC2 and ${ }_{\triangle \text { MALT1 }}$ HSC2 cells was compared with that of mock HSC2 cells by several sets of experiments. The conventional monolayered wound-healing assay on slide glasses showed $80.5 \%$ reduction in wound closure by wtMALT1 HSC2 cells and the $185.0 \%$ enhancement by $\triangle$ MALT1 HSC2 cells compared with the mock $\mathrm{HSC} 2$ cells (Figure 4A and B). The siRNA against MALT1 facilitated the wtMALT1 HSC2 cell wound closure $(P=0.003$; Figure $4 \mathrm{C}$; Supplementary Table 4). The ${ }_{\triangle \mathrm{MALT1}} \mathrm{HSC} 2$ cells did not respond to the siRNA because of the lack of binding site in its gene construct. To quantify it more accurately and continuously, the real-time wound-healing assay using the RTCA-DP system was performed. As shown in Figure 4D, the enhanced wound coverage by ${ }_{\triangle M A L T 1}$ HSC2 cells $(218.6 \%)$ and the reduction by ${ }_{\text {wtMALT1 }}$ HSC 2 cells $(66.4 \%)$ were confirmed. Since the wound closure reflects many aspects of cells (Yilmaz and Christofori, 2010), single cell migration was evaluated by the time-lapse analysis (Figure $4 \mathrm{E}$ ). Migration velocities of mock $\mathrm{HSC} 2$ cells were $1.01 \pm 0.05 \mu \mathrm{m} \mathrm{h}^{-1}$.

\begin{tabular}{|l|c|c|c|}
\multicolumn{4}{|l|}{ Table 2. Classification of gene sets by GO analysis } \\
\hline Category & $\begin{array}{c}\text { Total } \\
\text { gene }\end{array}$ & $\begin{array}{c}\text { Genes/ } \\
\text { input }\end{array}$ & P-value \\
\hline Nucleosome & 86 & 43 & $4.71 \mathrm{E}-12$ \\
\hline Protein-DNA complex & 105 & 43 & $3.55 \mathrm{E}-5$ \\
\hline Chromatin & 185 & 52 & $2.60 \mathrm{E}-6$ \\
\hline Basolateral plasma membrane & 146 & 24 & $1.03 \mathrm{E}-5$ \\
\hline Protein-DNA complex assembly & 112 & 46 & $2.79 \mathrm{E}-10$ \\
\hline Nucleosome assembly & 107 & 46 & $5.77 \mathrm{E}-10$ \\
\hline Chromatin assembly & 108 & 46 & $8.37 \mathrm{E}-5$ \\
\hline $\begin{array}{l}\text { Protein-DNA complex subunit } \\
\text { organisation }\end{array}$ & 117 & 46 & $1.66 \mathrm{E}-9$ \\
\hline Nucleosome organisation & 114 & 46 & $6.78 \mathrm{E}-9$ \\
\hline DNA packaging & 131 & 46 & $4.09 \mathrm{E}-4$ \\
\hline $\begin{array}{l}\text { Anatomical structure } \\
\text { morphogenesis }\end{array}$ & 811 & 26 & $3.77 \mathrm{E}-4$ \\
\hline Anatomical structure development & 1885 & 56 & $5.26 \mathrm{E}-8$ \\
\hline Tissue development & 500 & 31 & $7.63 \mathrm{E}-8$ \\
\hline Epidermis development & 133 & 29 & $2.00 \mathrm{E}-4$ \\
\hline System development & 1565 & 29 & $3.23 \mathrm{E}-7$ \\
\hline $\begin{array}{l}\text { Cellular component assembly at } \\
\text { cellular level }\end{array}$ & 459 & 46 & $4.76 \mathrm{E}-7$ \\
\hline Cellular component assembly & 677 & 46 & $4.85 \mathrm{E}-7$ \\
\hline DNA conformation change & 150 & 46 & $7.12 \mathrm{E}-7$ \\
\hline $\begin{array}{l}\text { Multicelluar organismal } \\
\text { development }\end{array}$ & 2064 & 162 & $9.95 \mathrm{E}-7$ \\
\hline Organ development & 1090 & 29 & $1.41 \mathrm{E}-6$ \\
\hline Developmental process & 2336 & 184 & $1.88 \mathrm{E}-6$ \\
\hline $\begin{array}{l}\text { Chromatin assembly or } \\
\text { disassembly }\end{array}$ & 150 & 49 & $4.28 \mathrm{E}-6$ \\
\hline Pathogenesis & & 39 & $1.19 \mathrm{E}-5$ \\
\hline Homophilic cell adhesion & & & \\
\hline Cell-cell adhesion & & & \\
\hline Abbreviation: GO =gene ontology. & & & \\
\hline
\end{tabular}

The $\triangle$ MALT1 HSC2 cells markedly quicken the velocities to $3.06 \pm$ $0.60 \mu \mathrm{m} \mathrm{h}^{-1}(P=0.021)$, and wtMALT1 HSC2 cells almost unmoved for $16 \mathrm{~h}\left(0.21 \pm 0.01 \mu \mathrm{m} \mathrm{h}^{-1} ; P=0.021\right)$.

\section{DISCUSSION}

A well-established role of NF- $\kappa \mathrm{B}$ activation by MALT1 in lymphocytes and enhanced NF- $\kappa \mathrm{B}$ activity in advanced oral carcinomas intimate that MALT1 promotes the carcinoma progression (Molinolo et al, 2009; McAllister-Lucas et al, 2011). However, MALT1 is expressed in normal oral epithelial cells and the loss of expression closely associates with the worse prognosis of carcinoma patients (Chiba et al, 2009). Then, we hypothesised that MALT1 has the differential role between epithelial cells and lymphocyte lineages, and analysed gene data sets that were affected by MALT1 in oral carcinoma cells to gain insights into this paradox. Most of the genes registered in 'NF- $\kappa$ B Signalling' in the IPA pathway database were unaffected or downregulated by MALT1, and the upregulated were limited to three genes (data not shown) among the $54 \mathrm{NF}-\kappa \mathrm{B}$-induced genes in head and neck carcinoma cells that were previously reported (Chung et al, 2006). 

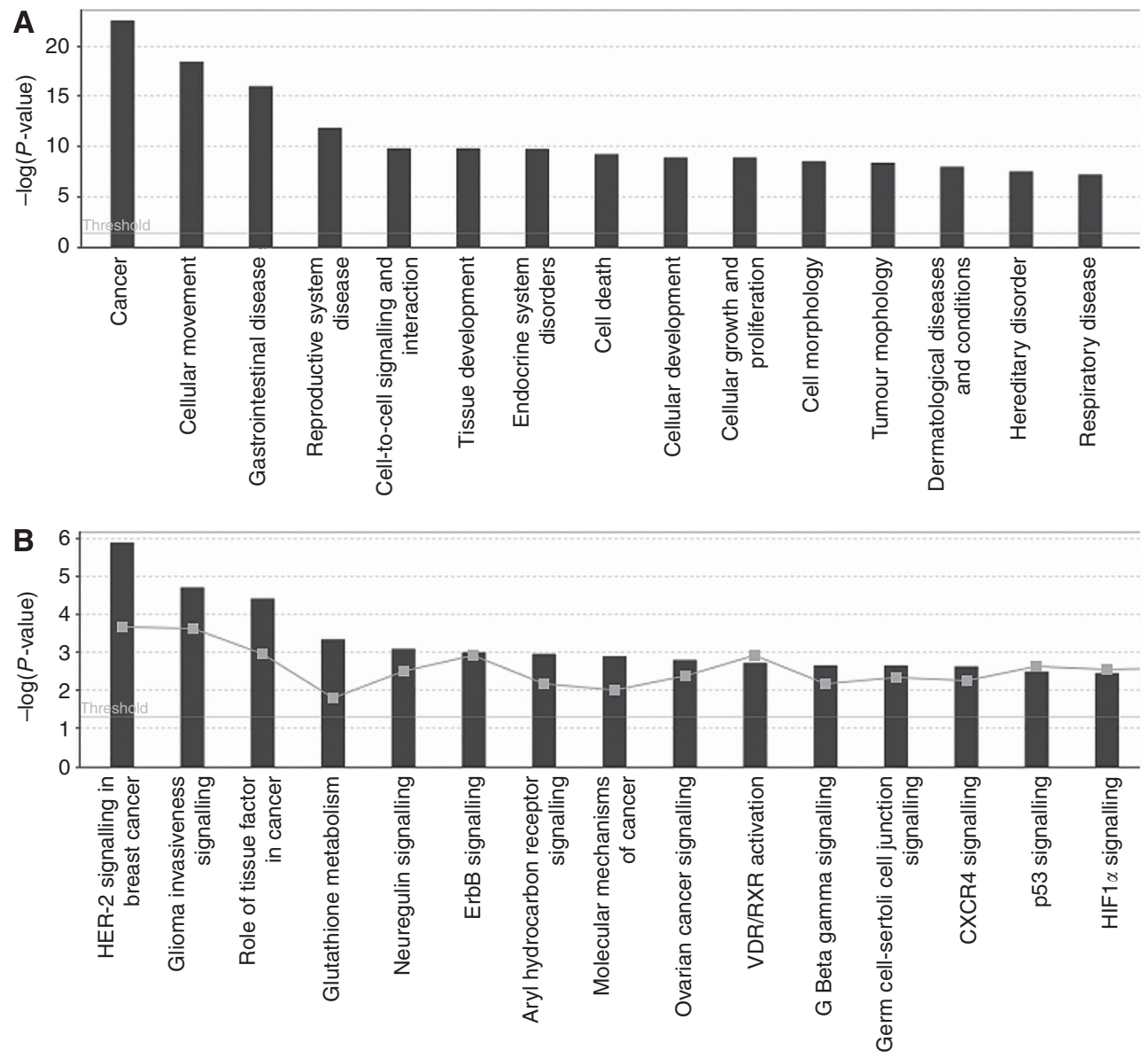

Figure 2. Ingenuity pathway analysis of the genes. The significance of each function or canonical pathway was determined based on the $P$-value by right-tailed Fisher's exact test and with threshold $<0.05$. The top 15 possible bio-functions (A) and canonical pathways (B) of genes regulated by MALT1 were shown. Ratio of number of genes in a given pathway satisfying the cutoff and total number of genes present in those pathways was determined by the pathway analysis.

Comparative analysis using IPA demonstrated that the genes downregulated by MALT1 affect EGF and TGF- $\beta$ pathways and cellular movement, suggesting the stimulation of oral carcinoma aggressiveness by loss of MALT1 expression.

EGFR encoding EGFR (ErbB1, HER-1), a most predominant EGF receptor in head and neck carcinomas (Bei et al, 2004), was downregulated. Although other EGF receptors (ErbB2-4) were upregulated, their expression and pathological role in head and neck carcinomas are a controversial issue (Schoppmann et al, 2010; Bussu et al, 2012; Zanaruddin et al, 2013). The EGFR ligands, AREG, TGFA, and EREG downregulated by MALT1, are overexpressed in oral carcinomas and stimulate proliferation of carcinoma cells (Rubin Grandis et al, 1996; Tsai et al, 2006; Shigeishi et al, 2008). Mucosa-associated lymphoid tissue 1 also downregulated EGF signalling molecules, RAS (HRAS and NRAS) and PKC (PKCA, PKCI, and PKCQ). The amplification of EGFR loci per se attributes to oral carcinoma development and progression (Sheu et al, 2009), and EGFR-mediated pathway is strongly activated in an aggressive subset of oral carcinoma with worse prognosis (Ang et al, 2002). Although the frequency of EGFR active mutation in oral carcinomas is controversial (Hsieh et al, 2011; Mclntyre et al, 2012), MALT1 may negatively regulate the pathway by the suppression of gene expression regardless of the presence or absence of mutation. These data suggest the liberation of EGF-EGFR pathway from the suppression upon loss of MALT1 expression.

In parallel with the suppressive role for EGF signalling gene expression, MALT1 downregulated TGFB2, TGFBR2, SMAD2,
SMAD3, and SMAD4. A protein complex made of these SMADs is crucial for the TGF- $\beta$-TGFBR2 signal transduction (Roberts and Wakefield, 2003). Although TGF- $\beta$ acts as a potent tumour suppressor at the early stage of carcinoma progression, it stimulates cell proliferation, invasion, metastasis, and angiogenesis at the late stage (Roberts and Wakefield, 2003). Loss of MALT1 expression occurs at the late stage of oral carcinoma progression (Chiba et al, 2009). Mucosa-associated lymphoid tissue 1 also downregulated genes encoding gp130 (IL6ST) and IL-11 (IL11), which stimulate carcinoma progression under the TGF- $\beta$ pathway (Calon et al, 2012). These data imply that the loss of expression facilitates oral carcinomas to activate TGF- $\beta$ signalling and pathway at the late stage of progression.

Since EGF and TGF- $\beta$ signalling frequently interact each other and co-regulate gene expression that enhance aggressive phenotypes of carcinoma cells (Kretzschamar et al, 1997; Wendt et al, 2010; Deharvengt et al, 2012), it is difficult to discern which signalling has a principal effect on the target gene expression in ${ }_{\text {wtMALT1 } 1}$ HSC2 cells. Of note, a mesenchyme-specific transcriptional factor, $H M G A 2$, that is upregulated by these signalling induces epithelial-mesenchymal transition (EMT) in carcinoma cells (Li et al, 1997; Thuault et al, 2006). Induction of the EMT gains carcinomas invasive and chemoresistant properties (Yilmaz and Christofori, 2010; Hanahan and Weinberg, 2011). HMGA2 is predominantly expressed at invasive front oral carcinoma cells showing the EMT and in the patients with worse prognosis (Miyazawa et al, 2004), and MALT1 expression rapidly declines at the invasive front carcinoma cells (Chiba et al, 2009). HMGA2 represses CDH1 expression through SNAI2, ZEB2, 


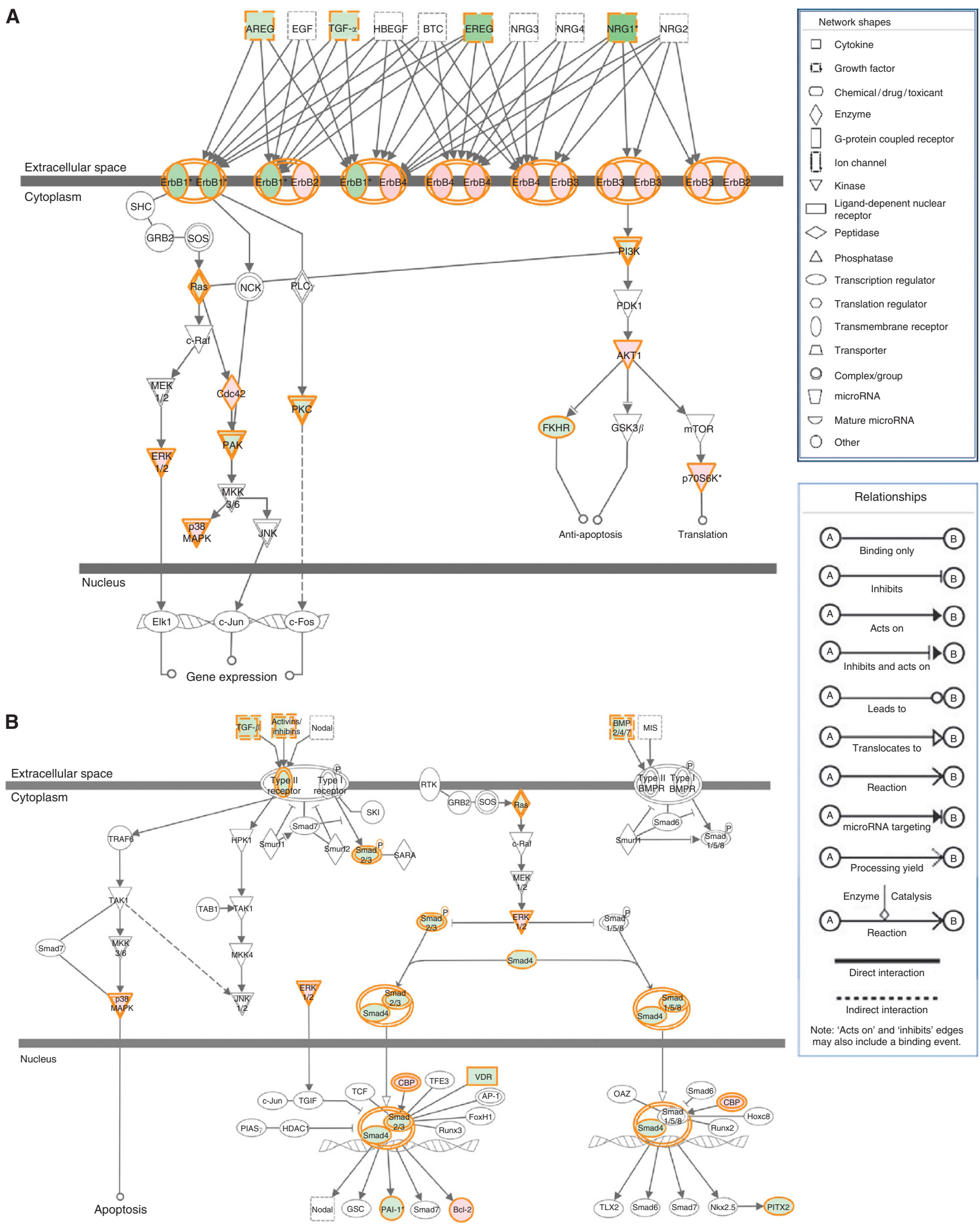

Figure 3. 'ErbB signalling' and 'TGF- $\beta$ pathway' in the canonical pathway. Functional interacting network among gene data sets was uploaded in the Ingenuity Pathway Analysis tool and the network of 'ErbB Signalling (A)' and 'TGF- $\beta$ pathway (B)'. Genes from our data set and falling in this network were shown in either red (upregulated) or green (downregulated).

and TWIST1 (Li et al, 1997; Thuault et al, 2008), which were downregulated in ${ }_{\text {wtMALT1 }} \mathrm{HSC} 2$ cells. As numbers of previous studies established a fact that inactivation of E-cadherin $(\mathrm{CDH} 1)$ expression is a critical determinant for aggressive carcinomas (Hanahan and
Weinberg, 2011; Hashimoto et al, 2012), expression status of MALT1 may have a great impact on oral carcinoma progression.

Mucosa-associated lymphoid tissue 1 also suppressed other EMT inducers (WNT3, FGFs, PDGFs, IL6R, and FGFRs) and 
A

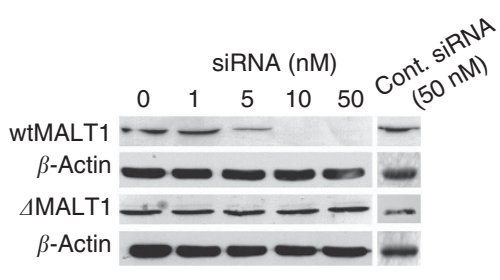

D

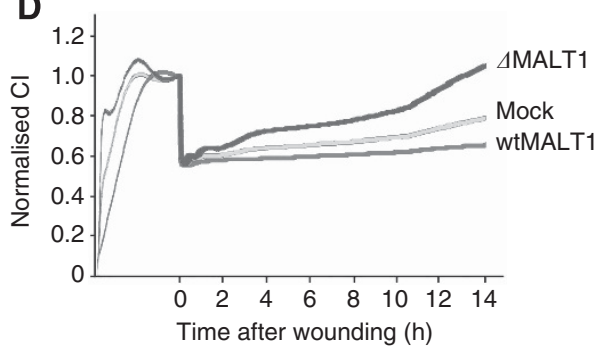

B

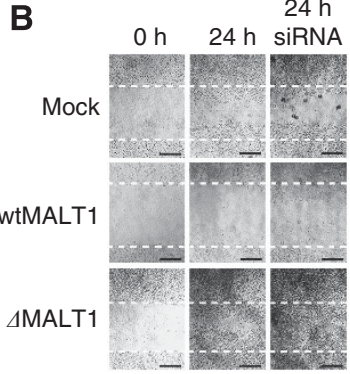

C $\%$

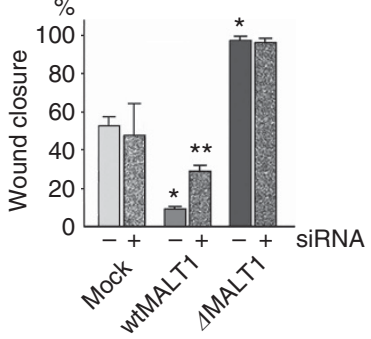

$\mathbf{E}$

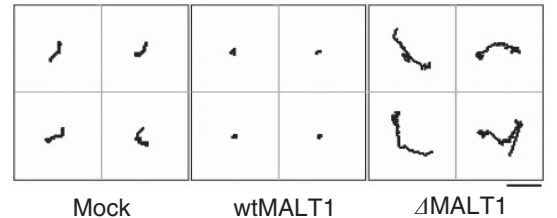

Figure 4. Migration of carcinoma cells. (A) Knock-down of MALT1 protein expression in wtMALT1 HSC2 cells and ${ }_{\triangle M A L T 1} \mathrm{HSC}_{2}$ cells by the siRNA against wtMALT1. The protein expression was probed by the immunoblotting using an anti-FLAG antibody. (B) Migration of cells $24 \mathrm{~h}$ after injury in the presence or absence of $50 \mathrm{~nm}$ MALT1 siRNA. White broken lines represent the original wound edges. Scale bar $=1 \mathrm{~mm}$. (C) Percentage of wound closure at $24 \mathrm{~h}$. The graph indicates means \pm s.d. of wound closure at $24 \mathrm{~h}(n=5)$. ${ }^{\star} P<0.001$ (compared with mock + siRNA) and ${ }^{\star \star} P<0.005$ (compared with wtMALT1 without siRNA). (D) Real-time sensing wound-healing assay. The coverage of wounds was monitored by the

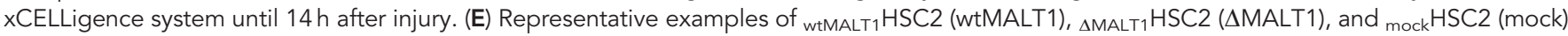
cell migration for $16 \mathrm{~h}$ using time-lapse microscopy $(n=4)$. Scale bar $=50 \mu \mathrm{m}$.

related genes encoding FAK signalling (integrins and paxillin), extracellular matrix-degrading enzymes (MMPs, ADAMs, plasminogen activators, kallikreins and cathepsins), CD44, SPARC, collagens, laminins, Jagged2, and podoplanin (Supplementary Table 1). It appears likely that loss of MALT1 expression activate the EMT machinery.

Enhanced migration is one of most representative characteristics of the EMT (Yilmaz and Christofori, 2010; Hanahan and Weinberg, 2011). Strong suppression of the migration by MALT1 supports our hypothesis that MALT1 has a distinct role in oral carcinoma cells from lymphoma cells. Since TGF- $\beta$ and EGF pathways synergistically accelerate the EMT and migration of carcinoma cells, their liberation from the suppression by MALT1 may have a key readout circuitry in oral carcinoma progression. Detailed analysis for the role of MALT1 on the pathways should contribute to understand the pathology of oral carcinomas and to develop novel therapeutic strategies for the carcinoma patients.

\section{ACKNOWLEDGEMENTS}

This study was supported by an institutional grant from the Nippon Dental University (to KI) and by grants from JSPS KAKENHI 22592080 (to TC) and 22592103 (to KI). This study is based on a thesis submitted to Graduate School of Dentistry, Meikai University, in partial fulfillment of the requirements for the Doctor of Dental Surgery degree.

\section{REFERENCES}

Ang KK, Berkey BA, Tu X, Zhang HZ, Katz R, Hammond EH, Fu KK, Milas L (2002) Impact of epidermal growth factor receptor expression on survival and pattern of relapse in patients with advanced head and neck carcinoma. Cancer Res 62: 7350-7356.

Ashburner M, Ball C, Blake J, Botstein D, Butler H, Cherry M, Tarver L, Kasarskis A, Lewis S, Matese JC, Richardson JE, Ringwald M, Rubin GM,
Sherlock G (2000) Gene ontology: tool for the unification of biology. Nat Genet 25: 25-29.

Bei R, Budillon A, Masuelli L, Cereda V, Vitolo D, Di Gennaro E, Ripavecchia V, Palumbo C, Ionna F, Losito S, Modesti A, Kraus MH, Muraro R (2004) Frequent overexpression of multiple ErbB receptors by head and neck squamous cell carcinoma contrast with rare antibody immunity in patients. J Pathol 204: 317-325.

Bussu F, Ranelletti FO, Gessi M, Graziani C, Lanza L, Paludetti G, Almadori G (2012) Immunohistochemical expression patterns of the HER4 receptors in normal mucosa and in laryngeal squamous cell carcinomas: antioncogenic significance of the HER4 protein in laryngeal squamous cell carcinoma. Laryngoscope 122: 1724-1733.

Calon A, Espinet E, Paloma-Pnnce S, Tauriello DVF, Iglesias M, Céspedes MV, Sevillano M, Nadal C, Jung P, Zhang XHF, Byrom D, Riera A, Rossel D, Mangues R, Massagué J, Sancho E, Batlle E (2012) Dependency of colorectal cancer on a TGF- $\beta$-driven program in stromal cells of metastasis initiation. Cancer Cell 22: 571-584.

Che T, You Y, Wang D, Tanner MJ, Dixit VM, Lin X (2004) MALT1/paracaspase is a signaling component down-stream of CARMA1 and mediates $\mathrm{T}$ cell receptor-induced NF-KB activation. J Biol Chem 279: 15870-15876.

Chiba T, Maeda G, Kawashiri S, Kato K, Imai K (2009) Epigenetic loss of mucosa-associated lymphoid tissue 1 expression in patients with oral carcinomas. Cancer Res 69: 7216-7223.

Choi S, Myers JN (2008) Molecular pathogenesis of oral squamous cell carcinoma: implications for therapy. J Dent Res 87: 14-32.

Chung CH, Parker JS, Ely K, Carter J, Yi Y, Murphy BA, Ang KK, El-Nagger AK, Zanation AM, Cmelak AJ, Levy S, Slebos RJ, Yarbrough WG (2006) Gene expression profiles identify epithelial-mesenchymal transition and activation of nuclear factor- $\mathrm{\kappa B}$ signaling as characteristic of high-risk head and neck squamous cell carcinoma. Cancer Res 66: 8210-8218.

Deharvengt S, Marmarelis M, Korc M (2012) Concomitant targeting of EGF receptor, TGF-beta and SRC points to a novel therapeutic approach in pancreatic cancer. PLoS One 7: e39684.

Edgar R, Domrachev M, Lash AE (2002) Gene Expression Omnibus: NCBI gene expression and hybridization array data repository. Nucleic Acids Res 30: $207-210$.

Hanahan D, Weinberg RA (2011) Hallmarks of cancer: the next generation. Cell 144: 646-674.

Hashimoto T, Soeno Y, Maeda G, Taya Y, Aoba T, Nasu M, Kawashiri S, Imai K (2012) Progression of oral squamous cell carcinoma accompanied 
with reduced E-cadherin expression but not cadherin switch. PLoS One 7: e47899.

Hsieh CH, Chang JW, Hsieh JJ, Hsu T, Huang SF, Liao CT, Wang HM (2011) Epidermal growth factor mutations in patients with oral cavity cancer in a betel nut chewing-prevalent area. Head Neck 33: 1758-1764.

Kawamoto Y, Ohyama Y, Chiba T, Yagishita H, Sakashita H, Imai K (2013) Proteomic identification of keratin alterations with enhanced proliferation of oral carcinoma cells by loss of mucosa-associated lymphoid tissue 1 expression. Int J Oncol (in press).

Kouros-Mehr H, Kim JW, Bechis SK, Werb Z (2008) GATA-3 links tumor differentiation and dissemination in a luminal breast cancer model. Cancer Cell 13: 141-152.

Kretzschamar M, Doody J, Massagué J (1997) Opposing BMP and EGF signaling pathways converge on the TGF-beta family mediator Smad1. Nature 389: 618-622.

Li D, Lin HH, McMahon M, Ma H, Ann DK (1997) Oncogenic raf-1 induces the expression of non-histone chromosomal architectural protein HMGI$\mathrm{C}$ via a p44/p42 mitogen-activated protein kinase-dependent pathway in salivary epithelial cells. J Biol Chem 272: 25062-25070.

Li Y, Basang Z, Ding H, Lu Z, Ning T, Wei H, Cai H, Ke Y (2011) Latexin expression is downregulated in human gastric carcinomas and exhibits tumor suppressor potential. BMC Cancer 11: 121.

Maeda G, Chiba T, Okazaki M, Satoh T, Taya Y, Aoba T, Kato K, Kawashiri S, Imai K (2005) Expression of SIP1 in oral squamous cell carcinomas: implications for E-cadherin expression and tumor progression. Int J Oncol 27: 1535-1541.

McAllister-Lucas LM, Baens M, Lucas PC (2011) MALT1 protease: a new therapeutic target in B lymphoma. Clin Cancer Res 17: 6623-6631.

Mclntyre JB, Bose P, Klimowicz AC, Brockton NT, Petrillo S, Matthews W, Easaw J, Magliocco A, Dort JC (2012) Specific and sensitive hydrolysis probe-based real-time PCR detection of epidermal growth factor receptor variant III in oral squamous cell carcinoma. PLoS One 7: e31723.

Miyazawa J, Mitoro A, Kawashiri S, Chada KK, Imai K (2004) Expression of mesenchyme-specific gene HMGA2 in squamous cell carcinomas of the oral cavity. Cancer Res 64: 2024-2029.

Mizunuma H, Miyazawa J, Sanada K, Imai K (2003) The LIM-only protein, LMO4, and the LIM domain-binding protein, LDB1, expression in squamous cell carcinomas of the oral cavity. Br J Cancer 88: 1543-1548.

Molinolo AA, Amornphimoltham P, Squarize CH, Castilho RM, Patel V, Gutkind JS (2009) Dysregulated molecular networks in head and neck carcinogenesis. Oral Oncol 45: 324-334.

Mori R, Xiong S, Wang Q, Tarabolous C, Shimada H, Panteris E, Danenberg KD, Danenberg PV, Pinski JK (2009) Gene profiling and pathway analysis of neuroendocrine transdifferentiated prostate cancer cells. Prostate 69: 12-23.

Nieman KM, Kenny HA, Penicka CV, Ladanyi A, Buell-Gutbrod Z, Zillhardt MR, Romero IL, Carey MS, Mills GB, Hotamisligil GS, Yamada SD, Peter ME, Gwin K, Lengyel E (2011) Adipocytes promote ovarian cancer metastasis and provide energy for rapid tumor growth. Nat Med 17: 1498-1503.

Ohmachi T, Inoue H, Mimori K, Tanaka F, Sasaki A, Kanda T, Fujii H, Yanaga K, Mori M (2006) Fatty acid binding protein 6 is overexpressed in colorectal cancer. Clin Cancer Res 12: 5090-5095.

Okamura H, Yoshida K, Haneji T (2009) Negative regulation of TIMP1 is mediated by transcription factor TWIST1. Int J Oncol 35: 181-186.

Roberts AB, Wakefield LM (2003) The two facets of transforming growth factor $\beta$ in carcinogenesis. Proc Natl Acad Sci USA 100: 8621-8623.

Rubin Grandis J, Melhem MF, Barnes EL, Tweardy DJ (1996) Quantitative immunohistochemical analysis of transforming growth factor-alpha and epidermal growth factor receptor in patients with squamous cell carcinoma of the head and neck. Cancer 78: 1284-1292.

Schmittgen DD, Livak KJ (2008) Analyzing real-time PCR data by the comparative $C_{T}$ method. Nat Protoc 6: 1101-1108.

Schoppmann SF, Jesch B, Friedrich J, Wrba F, Schultheis A, Pluschnig U, Maresch J, Hejna M, Birner P (2010) Expression of Her-2 in carcinomas of the esophagus. Am J Surg Pathol 34: 1868-1873.

Sheu JJ, Hua CH, Wan L, Yj Lin, Lai MT, Tseng HC, Jinawath N, Tsai MF, Chang NW, Lin CF, Lin CC, Hsieh LJ, Wang TL, IeM Shih, Tsai FJ (2009)
Functional genomic analysis identified epidermal growth factor receptor activation as the most common genetic event in oral squamous cell carcinoma. Cancer Res 69: 2568-2576.

Shigeishi H, Higashikawa K, Hiraoka M, Fujimoto S, Mitani Y, Ohta K, Takeichi M, Kamata N (2008) Expression of epiregulin, a novel epidermal growth factor ligand associated with prognosis in human oral squamous cell carcinomas. Oncol Rep 19: 1557-1564.

Shimada T, Nakamura H, Yamashita K, Kawata R, Murakami Y, Fujimoto N, Sato H, Seiki M, Okada Y (2000) Enhanced production and activation of progelatinase A mediated by membrane-type 1 matrix metalloproteinase in human oral squamous cell carcinomas: implications for lymph node metastasis. Clin Exp Metastasis 18: 179-188.

Siegel R, Naishadham D, Jemal A (2012) Cancer statistics, 2012. CA Cancer J Clin 62: 10-29.

Sossey-Alaoui K, Li X, Ranalli TA, Cowell JK (2005) WAVE3-mediated cell migration and lamellipodia formation are regulated downstream of phosphatidylinositol 3-kinase. J Biol Chem 280: 21748-21755.

Soutto M, Belkhiri A, Piazuelo MB, Schneider BG, Peng D, Jiang A, Washington MK, Kokoye Y, Crowe SE, Zaika A, Correa A, Peek Jr RM, El-Rifai W (2011) Loss of TFF1 is associated with activation of NF-kBmediated inflammation and gastric neoplasia in mice and human. J Clin Invest 121: 1753-1767.

Takayama S, Hatori M, Kurihara Y, Kinugasa Y, Shirota T, Shintani S (2009) Inhibition of TGF-beta1 suppresses motility and invasiveness of oral squamous cell carcinoma cell lines via modulation of integrins and downregulation of matrix-metalloproteinases. Oncol Rep 21: 205-210.

Thome M (2008) Multifunctional roles of MALT1 in T-cell activation. Nat Rev Immunol 8: 495-500.

Thuault S, Tan EJ, Peinado H, Cano A, Heldin CH, Moustakas A (2008) HMGA2 and Smads co-regulate SNAIL1 expression during induction of epithelial-to-mesenchymal transition. J Biol Chem 283: 33437-33446.

Thuault S, Valcourt U, Petersen M, Manfioletti G, Heldin CH, Moustakas A (2006) Transforming growth factor-beta employs HMGA2 to elicit epithelial-mesenchymal transition. J Cell Biol 174: 175-183.

Tsai ST, Yang KY, Jin YT, Lin YC, Chang MT, Wu LW (2006) Amphiregulin as a tumor promoter for oral squamous cell carcinoma: involvement of cyclooxygenase 2. Oral Oncol 42: 381-390.

Uraguchi M, Morikawa M, Shirakawa M, Sanada K, Imai K (2004) Activation of WNT family expression and signaling in squamous cell carcinomas of the oral cavity. J Dent Res 83: 327-332.

Wendt MK, Smith JA, Schiemann WP (2010) Transforming growth factor$\beta$-induced epithelial-mesenchymal transition facilitates epidermal growth factor-dependent breast cancer progression. Oncogene 29: 6485-6498.

Yamada T, Tsuda M, Ohba Y, Kawaguchi H, Totsuka Y, Shindoh M (2008) PTHrP promotes malignancy of human oral cancer cell downstream of the EGFR signaling. Biochem Biophys Res Commun 368: 575-581.

Yilmaz M, Christofori G (2010) Mechanism of motility in metastasizing cells. Mol Cancer Res 8: 629-642.

Yu N, Atienza JM, Bernard J, Blanc S, Zhu J, Wang X, Xu X, Abassi YA (2006) Real-time monitoring of morphological changes in living cells by electronic cell sensor arrays: an approach to study $\mathrm{G}$ protein-coupled receptors. Anal Chem 78: 35-43.

Zahm JM, Kaplan H, Hérard AL, Doriot F, Pierrot D, Somelette P, Puchelle E (1997) Cell migration and proliferation during the in vitro wound repair of the respiratory epithelium. Cell Motil Cytoskeleton 37: 33-43.

Zanaruddin SN, Saleh A, Yang YH, Hamid S, Mustafa WM, Khairul Bariah AA, Zain RB, Lau SH, Cheong SC (2013) Four-protein signature accurately predicts lymph node metastasis and survival in oral squamous cell carcinoma. Hum Pathol 44: 417-426.

This work is published under the standard license to publish agreement. After 12 months the work will become freely available and the license terms will switch to a Creative Commons AttributionNonCommercial-Share Alike 3.0 Unported License.

Supplementary Information accompanies this paper on British Journal of Cancer website (http://www.nature.com/bjc) 